НОВИТЕ СТАНДАРТНИ ДОГОВОРНИ КЛАУЗИ

ЗА ТРАНСФЕР НА ЛИЧНИ ДАННИ МЕЖДУ

ДЪРЖАВИ-ЧЛЕНКИ НА ЕС И ДЬРЖАВИ ИЗВЪН ЕС

гл. ас. д-р Диана Димитрова

Икономически университет - Варна

\title{
THE NEW STANDARD CONTRACTUAL CLAUSES FOR THE TRANSFER OF PERSONAL DATA BETWEEN EU AND NON-EU COUNTRIES
}

\section{Chief Assist. Prof. Diana Dimitrova PhD \\ University of Economics - Varna}

Резюме: В доклада е направен анализ на нововъведените с Решение за изпълнение (EC) 2021/914 на Комисията от 4 юни 2021 г. стандартни договорни клаузи като гаранция за защита на личните данни при трансфер между европейски държави и държави извън EC. Акцент е поставен на новите моменти. На базата на анализа и съпоставката с предходните общи договорни условия са направени обобщения и изводи.

Ключови думи: трансфер на лични данни, стандартни общи условия, гаранция за защчтта при предаване на лични данни

Abstract: In the report the new standard contractual clauses are analyzed, introduced with the Commission Implementing Decision 2021/914, and ensuring appropriate data protection safeguards in case of data transfers from the EU to third countries. Accent is put on the new moments. Based on the analysis and comparison with the previous standard contractual clauses summaries and conclusions are made.

Key words: transfer of personal data, standard contractual clauses, safeguards in case of data transfer

DOI: https://doi.org/10.36997/PPDD2021.106 


\section{Въведение}

Развитието на нашето общество в технологична насока и дигитализацията, с което неминуемо е свързано и събирането и обмен на лични данни както от публични органи, така и от частни дружества, налага строгото регулиране на правилата за трансфер за лични данни. На ниво Европейски съюз с приемането на Регламент (ЕC) 2016/679 на Европейския парламент и на Съвета от 27 април 2016 г. относно защитата на физическите лица във връзка с обработването на лични данни и относно свободното движение на такива данни и за отмяна на Директива 95/46/EO (Общ регламент относно защитата на данните $)^{1}$ бяха въведени единни правила за защита на физическите лица във връзка с обработване на личните данни. Тези правила се прилагат за Европейското икономическо пространство (ЕИП), което включва всички държави от ЕС и държави извън ЕС - Исландия, Лихтенщайн и Норвегия. Такава защита следва да бъде осигурена и в случаите, когато лични данни се прехвърлят извън Европейското икономическо пространство. С цел гарантиране преминаването на защитата заедно с данните са предвидени редица специални предпазни мерки като например решение относно адекватно ниво на защита съгласно чл. 45 от регламента или разработване на общи договорни клаузи за трансфер на лични данни съгласно чл. 46, пар. 1, които са предварително одобрени от Европейската комисия. ${ }^{2}$ При липса на решение на Комисията относно адекватното ниво на защита (чл. 45, пар. 3), съгласно чл. 46, пар. 1 от Регламент (ЕС) 2016/679 администраторьт или обработващият лични данни може да предава лични данни на трета държава само ако е предвидил подходящи гаранции и при условие, че са налице приложими права на субектите на данни и ефективни правни средства за защита. Съгласно чл. 28, пар. 7 и чл. 46, пар. 2, буква „в“ от Регламент (EC) 2016/679 подходяща гаранция при предване на лични данни на трета държава или международна организация могат да бъдат стандартни клаузи за защита на данните, приети от Комисията в съответствие с процедурата по разглеждане, посочена в чл. 93, пар. 2. Именно такива са приети с Решение за изпълнение (ЕС) 2021/914 на Комисията от 4 юни 2021 г.

OB, L 119, 2016, c. 1.

2 https:/ec.europa.eu/info/law/law-topic/data-protection/international-dimension-dataprotection/standard-contractual-clauses-scc_en 
относно стандартни договорни клаузи за предаването на лични данни на трети държави съгласно Регламент (EC) 2016/679 на Европейския парламент и на Съвета. ${ }^{3}$ Тези модернизирани стандартни договорни клаузи са издадени пет години след приемане на регламента и следва да заменят предходните такива съгласно Директива 95/46 за защита на данните.

Актуалността на темата е безспорна предвид скорошното приемане на новите стандартни договорни клаузи. Именно това провокира интереса на автора като в доклада те са изследвани и съпоставени с предходните такива в Решение на Комисията от 15 юни 2001 г. относно общите договорни клаузи за трансфера на лични данни към трети страни съгласно Директива 95/46/EO, ${ }^{4}$ Решение на Комисията от 27 декември 2004 г. за изменение на Решение 2001/497/EО за въвеждане на алтернативен комплект общи договорни клаузи за прехвърляне на лични данни в трети страни ${ }^{5}$ и Решение на Комисията от 5 февруари 2010 г. относно стандартните договорни клаузи при предаването на лични данни към лицата, които ги обработват, установени в трети страни, съгласно Директива 95/46/ЕО на Европейския парламент и на Съвета. ${ }^{6}$

Разработката има за цел анализ на действащите стандартни договорни клаузи като гаранция за защитата на личните данни при трансфер. Акцентирано е върху новите моменти при тази защита. На база на анализа са направени обобщения и изводи.

Използвани са методите на индукция и дедукция, нормативен и сравнителноправен анализ за постигане на целта на разработката и свързаните с нея изследователски задачи. Предвид ограничения обем авторът не претендира за изчерпателност на изследвания въпрос.

Докладът е съобразен с регламентацията в законодателството на Европейския съюз (ЕС) към 30.09.2021 г.

\section{Изложение}

Свидетели сме на значителни промени в цифровата икономика, характерни за които са: използването на нови и по-сложни операции

\footnotetext{
OB, L199, 2021, c. 31.

OB, L181/19, 2001, c. 70.

OB, L385/74, 2004, c. 72 .

OB, L 39, 2010, c. 5.
} 
по обработване, множество вносители и износители на данни, дълги и сложни вериги на обработване и непрекъснато развиващи се стопански взаимоотношения. Бързото развитие обуславя и необходимостта от модернизиране на стандартните договорни клаузи, за да могат те да отразят адекватно тези реалности и да обхванат допълнителни ситуации на обработване и предаване. Приетите с решение за изпълнение на Комисията (EC) 2021/914 стандартни договорни клаузи (СДК) са съобразени както актуалните разпоредби на Регламент (ЕС) 2016/679, така и със Съвместно становище 2/2021 на ЕКЗД и ЕНОЗД във връзка с Решението за изпълнение на Европейската комисия относно общите договорни клаузи за трансфера на лични данни към трети държави по въпросите, посочени в чл. 46, пар. 2, буква „в“ от Регламент (ЕC) 2016/679.

В раздел едно са включени цел и обхват на клаузите, действие, трети страни - бенефициенти, тълкуване, йерархия, описание на предаването (в Приложение ІБ на договора), както и незадължителната клауза за присъединяване на други страни към договора. Подобно на новите и предходните СДК съдържат клауза в полза на трето лице и при тях описанието на предаването е предвидено да бъде направено в Допълнение 1 към договора. За разлика от предходните СДК, където в клауза 1 са дадени определения - лични данни, вносител на данни, износител на данни и т.н., в новите СДК има различен подход - в клауза 4 за тълкуване на използваните термини се препраща към Регламент (ЕС) 2016/679. Разлика има и при мястото на разпоредбата относно изменението на СДК - в предходните то е регулирано в последните договорни условия, в новите това е направено още в клауза 2. В клаузата за изменение на договора във варианта от 2001 г. е предвидено клаузите да не подлежат на изменение, а във варианта от 2010 г. - отново да не бъдат променяни или изменяни, а само при необходимост да бъдат прибавяни клаузи по търговски въпроси, които не им противоречат. Забраната за промяна е възприета и в новия вариант, като изменение се допуска с цел да се избере подходящият(ите) модул(и) или да се добави или актуализира информация в допълнението. И тук страните биха могли да добавят други клаузи или допълнителни гаранции, при условие че те не противоречат, пряко или непряко, на стандартните клаузи или не засягат основни права или свободи на субектите на данни, а също така и да включат стандартните договорни клаузи в по-широк договор. За разлика от предходните 
варианти в новите СДК е дадена възможност и за по-гъвкав подход по отношение на броя на страните, които могат да се присъединят към такъв договор. Съгласно незадължителната клауза 7 за присъединяване: „структура, която не е страна по клаузите, може със съгласието на страните да се присъедини към тях по всяко време или като износител на данни, или като вносител на данни, като попълни допълнението и подпише приложение I.A.“ Това дава възможност за присъединяване на повече страни към СДК от момента на подписване на документите, като не се пораждат права или задължения за присъединяващата се структура за периода преди тя да стане страна.

В раздел II „Задължения на страните“ - новите стандартни договорни клаузи са предвидили нов модел, в който са съчетани, от една страна, общи клаузи, а от друга - модулен подход със създадени отделни модули за различни сценарии на трансфер на данни:

- Модул 1 - предаване на данни от аминистратор на администратор.

- Модул 2 - предаване на данни от аминистратор на обработващ лични данни.

- Модул 3 - предаване на данни от обработващ лични данни на обработващ лични данни.

- Модул 4 - предаване на данни от обработващ лични данни на администратор.

Направен е опит да бъдат обхванати различните възможности на предаване, като се отчита сложността на съвременните вериги на обработване. В зависимост от вариантите на предаване администраторите и обработващите лични данни следва да избират към общите клаузи приложимия модул, като по този начин задълженията им по СДК биват съобразени с тяхната роля и отговорности в този процес. Някои от клаузите са еднакви за всички модули - например клауза 14 „Местно законодателство и практики, засягащи спазването на клаузите“. При други се наблюдава групиране - например в клауза 12 „Отговорност“ - модулите са групирани в две групи: в едната - модул 1 и 4, в другата - модул 2 и 3, а при трети са предвидени отделни разпоредби за всеки модул - например клауза 8 ,Гаранция за защита на личните данни“. За разлика от това ново решение в предходните варианти на СДК няма диференциране в модули, в зависимост от вида на предаването на данните, клаузите са еднакви за всички варианти. 
В клауза 9 е регулацията за използване на подизпълнители, като има отделен набор за модул 2 и модул 3 . И за двата модула се предвиждат по 2 варианта - със специфично писмено разрешение или с общо писмено разрешение. В първия случай вносителят на данни не предава за подизпълнение на дейностите си по обработване без специфичното предварително писмено разрешение на износителя на данни, а във втория вносителят на данни има общото разрешение на износителя на данни да включва обработващ(и) лични данни подизпълнител(и) от сьгласуван списьк. За разлика в предходните СДК от 2001 г. липсва разпоредба за подизпълнител, а от 2010 г. е предвидена само възможността за предаване за подизпълнение с предварително писмено съгласие.

В клауза 10 „Права на субектите на данни“ в различните 4 модули е регулирано процедирането при обработка на искане от субекта на данните, а в клауза 11 „Правни средства за защита“- задължение за предоставяне на информацията за обработване на жалби за модули 1 - 3. Правната защита на субектите на данни следва да бъде улеснена, като в СДК се предвижда вносителят да уведомява субектите на данни за координати за връзка с точка за контакт, както и своевременното обработване на всички искания и жалби. Клауза 11, както и клауза 13 „Надзор“ не включват модул 4, а при клауза 12 „Отговорност“ са предвидени регулации за двете отделни групи - на модул 1 и 4 и на модул 2 и 3. За гарантиране на ефективен надзор вносителят на данни следва да приеме юрисдикцията и да си сътрудничи с компетентния надзорен орган и съдилищата и да се ангажира да спазва всяко задължително решение съгласно приложимото право на държавата членка. По-специално вносителят на данни следва да приеме да отговаря на запитвания, да бъде подлаган на одити и да спазва мерките, приети от надзорния орган, включително коригиращите и компенсаторните мерки.

В следващия раздел III - „Местно законодателство и задължения в случай на достъп на публични органи“ - отново са посочени модулите, но разпоредбите на клауза 14 „Местно законодателство и практики, засягащи спазването на клаузите“, както и клауза 15 „Задължения на вносителя на данни в случай на достъп от страна на публични органи“ важат за всички модули. Този раздел следва да предвиди гаранции за спазване на клаузите при правнообвързващи искания от публични органи в тази държава за разкриване на предадените 
лични данни с оглед на съдебната практика на Съда на Европейския съюз. ${ }^{7}$ Съгласно клауза 15.2 „вносителят на данни приема да провери законосъобразността на искането за разкриване, по-специално дали то продължава да е в правомощията, предоставени на отправилия го публичен орган, както и да оспори искането, ако след внимателна преценка стигне до заключението, че има разумни основания да се смята, че искането е незаконосъобразно съгласно законодателството на държавата на получаване, приложимите задължения сьгласно международното право и принципите на международната вежливост. Вносителят на данни следва при същите условия да търси възможности за обжалване.“

Раздел IV „Заключителни разпоредби“ включва клауза 16 „Неспазване на клаузите и прекратяване“ и клауза 17 „Приложимо право“. В първата са предвидени възможностите за прекратяване, както и задължения за уведомяване от страна на вносителя при невъзможност да спазва клаузите - общо, без разделение по модули. В следващата отново има разделение по модули като за модули 1 - 3 приложимото право е това на страна - членка на ЕC, а за модул 4 следва да бъде посочено правото на държавата (не задължително страна членка на ЕС).

Разпоредбите от раздели II, III и IV липсват в този обем и подробности в предходните СДК. В тях, в рамките на 11 - 12 значително по-семпло и кратко формулирани клаузи, е направено разделение на задължения на износител и задължения на вносител на данни, както има и клаузи по отношение на отговорност, посредничество и юрисдикция/медиация и съд, сътрудничество с надзорните органи, приложимо право, изменение на договора, предаване за подизпълнение и задължения след приключване на услугите по обработване.

Както беше посочено по-горе, и при предходните, и при новите СДК е предвидено част от информацията да бъде дадена в допълненията/приложенията към договора, а именно - описание на предаването и технически и организационни мерки, във варианта от 2001 г. липсват техническите и организационните мерки, но има задължителни принципи за защита на данните в допълнения 2 и 3 . В предходните

7 EDPB - EDPS Joint Opinion 2/2021 on the European Commission's Implementing Decision on standard contractual clauses for the transfer of personal data to third countries, p. 7, (https://edpb.europa.eu/sites/default/files/files/file1/edpb_edps jointopinion_202102_art46sces_en.pdf). 
СДК в допълнение 1 е включено описание на дейностите, свързани с предаването от износител и вносител, засегнатите категории физически лица, категориите данни, крайни цели на трансфера (СДК 2001 г.), специални категории данни (СДК 2010 г.)/чувствителни данни (СДК 2001 г.) и операции по преработване (СДК 2010 г.)/ адресати, пред които може да се разгласяват данните и ограничение на съхранението (СДК 2001 г.). В приложение I, за модули 1 - 4 на новите СДК са предвидени три части: „А“ - списьк на страните; „Б“ - описание на предаването и „В“ - компетентен надзорен орган. В описанието на предаването освен категориите субекти на лични данни, предавани лични данни и чувствителни лични данни са включени и новите: честота на преработване (еднократно или текущо), естество на обработване, цели и срок, за който ще се съхраняват личните данни, а ако това е невъзможно - критериите, използвани за определяне на този срок. В приложение II „Технически и организационни мерки, включително технически и организационни мерки за осигуряване на сигурността на данните“ за модулите 1 - 3 са разписани изключително подробно примери за възможни мерки, като те трябва да бъдат описани конкретно, а не общо. Има и приложение III за модули 2 и 3 - списък на обработващите лични данни подизпълнители, като то се попълва в случай на специфично разрешение за използване на обработващи лични данни подизпълнители (клауза 9, буква „а““, вариант 1).

При направения сравнителен анализ бе установено, че в новите СДК е предвиден нов модел на съчетаване на модули с общи клаузи. Отделните клаузи са значително по-подробни и детайлни, те обхващат различните видове предаване на лични данни между администратори и обработващи лични данни и създават гаранции, че защитата на личните данни, осигурена на европейско ниво от Регламент (EC) 2016/679, преминава заедно с трансфера на данни към трети държави.

\section{Заключение}

Приемането на нови стандартни договорни клаузи е обусловено както от динамично променящите се обществени отношения, свързани с дигитализацията, така и от необходимостта те да са в съответствие с изискванията за предоставяне на подходящи гаранции на защитата на личните данни при трансфер съгласно разпоредбите на 
Регламент (ЕС) 2016/679. На 4 юни 2021 г. съгласно чл. 46, пар. 2, буква „в“ и в съответствие с процедурата по разглеждане, посочена в чл. 93, пар. 2 от Регламент (ЕС) 2016/679 с Решение за изпълнение (EC) 2021/914 на Комисията бяха въведени новите стандартни договорни клаузи осигуряващи подходящата гаранция.

След проведения анализ се налага изводът, че при приемането им са отчетени както промените в обществените отношения във връзка с дигитализацията и промените в нормативната уредба, така и Съвместното становище 2/2021 на ЕКЗД и ЕНОЗД във връзка с Решението за изпълнение на Европейската комисия относно общите договорни клаузи за трансфера на лични данни към трети държави по въпросите, посочени в чл. 46, пар. 2, буква „в““ от Регламент (ЕС) 2016/679. Въведени са редица нови моменти като нов модел на съчетаване на модули с общи договорни клаузи, възможност и други страни да се присъединяват към договорните клаузи, възможност за използване на СДК при трансфер на лични данни към подизпълнител, улеснена правната защита на субектите на данни, гаранции за спазване на клаузите при правнообвързващи искания от публични органи, по-подробно и детайлно описание на предаването и на техническите и организационни мерки в приложенията. В Съвместно становище на ЕКЗД и Европейския надзорен орган по защита на данните (ЕНОЗД) относно СДК за трансфер на данни към трети страни се поставя въпрос във връзка с въведените модули за различни сценарии на трансфер - дали е възможно в едни СДК да се съдържат няколко модула в зависимост от ситуациите или за всяка ситуация и модул следва да сключат отделни договори. Предложението към Комисията е да се обърне внимание на това в рубрика „Въпроси и отговори“ и да се изясни, че комбинирането на различни модули в едни СДК не може да води до размиване на отговорността. ${ }^{8}$ При приложението на СДК на практика ще възникнат и редица други въпроси и то ще покаже доколко ефективна гаранция и защита предлагат те. Предвид факта, че нуждите на заинтересованите страни могат да се променят, а технологиите и операциите по обработване се променят бързо в условията на дигитализация, Комисията следва да оценява действието

8 EDPB-EDPS JointOpinion2/2021 on theEuropeanCommission's Implementing Decision on standard contractual clauses for the transfer of personal data to third countries, p. 9 , (https://edpb.europa.eu/sites/default/files/files/file1/edpb_edps_jointopinion_202102_ art46sccs_en.pdf). 
на стандартните договорни клаузи в светлината на натрупания опит като част от периодичната оценка на Регламент (ЕС) 2016/679, предвидена в член 97.

\section{Използвана литература}

EDPB - EDPS Joint Opinion 2/2021 on the European Commission's Implementing Decision on standard contractual clauses for the transfer of personal data to third countries, ( https://edpb.europa.eu/sites/default/ files/files/file1/edpb_edps_jointopinion_202102_art46sccs_en.pdf, 30.09.2021).

OB, L 119, 2016, c. 1.

OB, L199, 2021, c. 31.

OB, L181/19, 2001, c. 70 .

OB, L385/74, 2004, c. 72 .

OB, L 39, 2010, c. 5

https://ec.europa.eu/info/law/law-topic/data-protection/ international-dimension-data-protection/standard-contractual-clausesscc_en

За контакти: гл. ас. д-р Диана Димитрова Икономически университет - Варна dianadim@ue-varna/bg 